\title{
1 Effect of alkaline and high-pressure homogenization 2 on the extraction of phenolic acids from potato peels
}

4 Xindi Zhu ${ }^{\mathrm{a}, \mathrm{b}}$, Yanling Cheng ${ }^{\mathrm{b}, \mathrm{c}}$, Paul Chen ${ }^{\mathrm{b}}$, Peng Peng ${ }^{\mathrm{b}}$, Shiyu Liu ${ }^{\mathrm{b}}$, Dong Li ${ }^{\mathrm{a},{ }^{*}}$, 5 Roger Ruan ${ }^{\mathrm{b}, *}$

$6 \quad{ }^{a}$ College of Engineering, China Agricultural University, Beijing 10083, China

$7 \quad{ }^{b}$ Center for Biorefining and Department of Bioproducts and Biosystems Engineering,

8 University of Minnesota, 1390 Eckles Ave., St. Paul, MN 55108, USA

$9{ }^{c}$ Biochemical Engineering College, Beijing Union University,Beijing 100023, China

11 * Corresponding author: Yangtze Scholar Distinguished Guest Professor, Nanchang University, and

12 Professor, University of Minnesota, 1390 Eckles Ave., St. Paul, MN 55108, USA. Tel.: +1 612625

13 1710; fax: +1 6126243005 (R.Ruan). College of Engineering, China Agricultural University, P.O.

14 Box 50, 17 Qinghua Donglu, Beijing 100083, China. Tel./fax: +86 10 62737351(Dong Li)

15 E-mail address: ruanx001@umn.edu (R. Ruan).dongli@cau.edu.cn(Dong Li)

16 A B S T R A C T

17 Phenolic acids were extracted from potato peels with $\mathrm{NaOH}$ treatment and a 18 high-pressure homogenization (HPH) process. Total phenolic content, total

19 flavonoid content, 2,2-diphenyl-1-picrylhydrazyl (DPPH) radical scavenging capacity

20 and extraction yield were determined with different treatment conditions. 
21 Significant improvement was observed after the alkaline and HPH treatments. HPLC

22 analysis shows that the phenolic compounds contained gallic acid, sinapic acid,

23 vanillic acid, syringic acid, protocatechuic acid, $p$-coumaric acid, chlorogenic acid,

24 caffeic acid and ferulic acid. The yields of these specific phenolic acids varied with

25 different treatments. Scanning electron microscope, nuclear magnetic resonance and

26 particle size measurements suggest that changes in cellular structure may be the

27 mechanisms for the improvement in extraction rendered by the $\mathrm{HPH}$ and $\mathrm{NaOH}$

28 treatments. In conclusion, the combined treatment of $\mathrm{NaOH}$ and $\mathrm{HPH}$ increased the

29 extraction yield and functionality of the phenolic acids from the potato peel

30 residues.

$31 \quad$ Keywords:

32 Potato peel

33 Phenolic acid

34 High-pressure homogenization

$35 \mathrm{NaOH}$ treatment

\section{Introduction}

37 Potatoes are a major crop in the world. In 2013, 376.45 million tons of potatoes

38 were produced (FAOSTAT). One third of the production was consumed as a fresh

39 product while the rest went into processing flow to meet the demands for

40 convenience and fast food consumptions, which include frozen fries and wedges, 
41 crisps, starch and dried potatoes. During processing, most potatoes need to be

42 peeled with various methods, resulting in a large amount of potato peel residues.

43 The potato peel residues from food processing contain starch, non-starch

44 polysaccharide, protein, and fat. Therefore, it has been used as a carbon source in

45 fermentation to produce lactic acid, biofuels (Arapoglou, Varzakas, Vlyssides, \&

46 Israilides, 2010), reducing sugars (Bhattacharyya, Chakraborty, Datta, Drioli, \&

47 Bhattacharjee, 2013), and cellulolytic enzymes (dos Santos, Gomes, Bonomo, \&

48 Franco, 2012). Phenolic compounds and glycoalkaloids are found in potatoes,

49 especially in potato peels. Ferulic acid, gallic acid, sinapic acid, vanillic acid, caffeic

50 acid, syringic acid, protocatechuic acid, $p$-coumaric and chlorogenic acid have been

51 extracted and identified in potato peels (Friedman, 1997; Maldonado, Mudge, Ganzle,

52 \& Schieber, 2014). Higher quantities and stronger antioxidant activity of these acids

53 were observed in potato peels than in potato flesh $(\underline{\mathrm{Wu}}, \mathrm{Xu}, \mathrm{Ma}, \mathrm{Cao}, \mathrm{Ma}, \& \mathrm{Ma}, 2012)$.

54 These phenolic compounds have been proven to be an source of natural antioxidants,

55 which can replace unhealthy anti-oxidant additives used in food products, such as

56 butylated hydroxyanisole, butylated hydroxytoluene, tert-butyl hydroquinone

57 (Rehman, Habib, \& Shah, 2004). These natural antioxidants can retard the oxidation

58 of proteins and lipids while exhibiting antimicrobial activity. They have been used in

59 radiated lamb meat (Kanatt, Chander, Radhakrishna, \& Sharma, 2005), chilled

60 minced horse mackerel (타rvin, Grejsen, \& Jacobsen, 2012), soy bean oil (ㄹehman, 
61 Habib, \& Shah, 2004), vegetables oil (A. A. A. Mohdaly, Sarhan, Mahmoud, Ramadan,

62 \& Smetanska, 2010), among other uses.

63 The phenolic acids may exist in free or bound form in potato peels. Most methods

64 can isolate almost all of the free phenolic acids, but a smaller percentage of the

65 bound phenolic acids. Most of ferulic acid and $p$-coumaric acid found in plants are

66 bound to the cell wall polysaccharides through ester-bonds (Fry, 1986). The bound

67 form phenolic acids can potentially offer strong antioxidant capacity if they are

68 released from the cellular matrix (Nara, Miyoshi, Honma, \& Koga, 2006). Alkaline

69 treatments such as dilute sodium hydroxide solution have been shown to break the

70 ester-bonds and release the bound form phenolic acids, resulting in a higher total

71 yield of phenolic acids (Nara, Miyoshi, Honma, \& Koga, 2006).

72 There have been many studies on the conventional methods for extraction of

73 phenolic compounds from potato peels, using organic solvents such as methanol,

74 acetone, ethanol, and ethyl acetate at high temperatures. It has been shown that

75 methanol and ethanol can extract more phenolic acids from potato peels compared

76 to acetone, hexane, diethyl ether and petroleum ether(Adel A. A. Mohdaly, Sarhan,

77 Smetanska, \& Mahmoud, 2010). In addition, a few new methods have been

78 developed to extract the active components in potato peels and other crop residues.

79 These include ultrasonic assisted extraction (Chen, Zhao, \& Yu, 2015), subcritical

80 water or pressurized liquid extraction at above $100{ }^{\circ} \mathrm{C}$ under high pressure (Alvarez, 
81 Cahyadi, Xu, \& Saldana, 2014; P. P. Singh \& Saldana, 2011), acidified water- and

82 ethanol-based solvents (Maldonado, Mudge, Ganzle, \& Schieber, 2014), and

83 microwave-assisted extraction (A. Singh, Sabally, Kubow, Donnelly, Gariepy, Orsat, et

84 al., 2011).

85 High-pressure homogenization ( $\mathrm{HPH})$ has been reported to reduce particle size

86 dramatically (Grau, Kayser, \& Müller, 2000; Li, Ruan, Chen, Liu, Pan, Lin, et al., 2004),

87 and is used for pharmaceuticals, food and other materials manufacturing industries.

88 Homogenization is mainly a mechanical process that disrupts cellular structures; for

89 example, it breaks cell walls and compartments, resulting in the direct release of

90 cellular products and increased access of solvent to cellular materials.

91 Microfluidization, the HPH technique used in this study, can generate $160 \mathrm{Mpa}$,

92 whereas conventional homogenization techniques usually generate $30 \mathrm{Mpa}$. In the

93 microfluidization technique, high velocity micro-streams are created as a fluid

94 accelerates into chambers so that the high impact shear can damage the cell walls

95 and reduce the particle size more significantly (McCrae, 1994).

96 However, there is no report on the use of a method combining HPH and alkaline

97 treatment to extract phenolic acids from potato peels. This research seeks to

98 compare a combined method to alkaline treatment and HPH methods used

99 separately; to study the effect of alkaline treatment time and concentration on the

100 yield of total phenolic acid, total flavonoids and radical scavenging capacity; and to 
101 determine the effect of the combined treatment process on the yield of individual

102 major phenolic acids.

103 2. Materials and Methods

$104 \quad 2.1$ Materials and chemicals

105 The potato peel residues were provided by Old Dutch Food Inc. (Roseville, MN,

106 USA). HPLC-grade acetonitrile and water were purchased from Sigma-Aldrich (St.

107 Louis, MO, USA). Phenolic standards of highest purity available were used. Ferulic

108 acid (FER), gallic acid (GAR), sinapic acid (SIN), vanillic acid (VAN), caffeic acid (CAF),

109 syringic acid (SYR), protocatechuic acid (PRO), $p$-coumaric acid ( $p$-COU) and

110 chlorogenic acid (CHL) were obtained from Sigma-Aldrich (St. Louis, MO, USA). All

111 other chemicals were analytical grade ordered from Sigma-Aldrich (St. Louis, MO,

112 USA).

1132.2 Sample preparation, chemical analysis and experiment procedure

114 Potato peels were lyophilized and milled with a laboratory bench mill, and then

115 screened by sieves. The samples with particle size between $125 \mu \mathrm{m}$ and $355 \mu \mathrm{m}$ were

116 used for the extraction experiments. The chemical composition of potato peels was

117 analyzed by the Minnesota Valley Testing Laboratories, Inc (New Ulm, MN, USA). The

118 moisture (AOAC 930.15), carbohydrate (calculated), fat (AOAC 2003.05), crude fiber 
119 (AOCS BA6A-05), protein (AOAC 990.03), starch (MVTL R\&D) and ash (AOAC 942.05)

120 were determined before the process. The extraction procedure is as follows: $4 \mathrm{~g}$

121 potato peel residue power was pretreated in ethanol with $100 \mathrm{ml} \mathrm{NaOH}$ of varying

122 concentration $(0-0.4 \mathrm{~mol} / \mathrm{L})$ at $40^{\circ} \mathrm{C}$ for varying amounts of time $(0-24 \mathrm{~h})$. Table 2

123 shows the experimental conditions used for each sample. Sample Number 1 is the

124 control sample that did not go through the $\mathrm{NaOH}$ pretreatment and $\mathrm{HPH}$ process.

125 After that, the samples were neutralized with HCL in ethanol to pH 7.0 and passed

126 through the High Pressure Homogenizer twice at 158.58 Mpa. All samples were

127 diluted with ethanol to $200 \mathrm{~mL}$ and incubated at $40{ }^{\circ} \mathrm{C}$ for $1 \mathrm{~h}$ for extraction. In

128 succession, the samples were centrifuged at $8000 \mathrm{rpm}$ for $10 \mathrm{~min}$ and filtrated

129 through a $0.45 \mu \mathrm{m}$ membrane. The upper layer liquid (supernatant) was collected

130 and stored in $-20^{\circ} \mathrm{C}$ for further testing.

1312.3 Determination of total phenolic content

132 A modified Folin-Ciocalteu assay (Singleton, 1999) was employed to determine

133 the total phenolic content of potato peel extracts. Gallic acid was used as a standard

134 and a series of gallic acid solutions $(0-100 \mathrm{mg} / \mathrm{L})$ was prepared to establish the

135 standard curve, which was a plot of gallic acid concentration vs. absorbance at 760

$136 \mathrm{~nm}$. For the analysis, $100 \mu \mathrm{L}$ Folin-Ciocalteu Reagent was added to $1 \mathrm{~mL}$ sample or

137 blank. After $5 \mathrm{~min}, 1 \mathrm{~mL} \mathrm{Na} 2 \mathrm{CO}_{3}$ solution (12\%) was added, followed by addition of 5 
$138 \mathrm{~mL}$ distilled water. After incubation for $1 \mathrm{~h}$ at room temperature, the absorbance of

139 samples was measured on a DR5000 Spectrophotometer (Hach Compary, Germany)

140 at $760 \mathrm{~nm}$ in a $1 \mathrm{~mL}$ cuvette. The results were expressed as mg gallic acid

141 equivalent/g dry weight (mg GAE/g DW).

142 2.4 Determination of total flavonoid content (TFC)

143 The total flavonoid content was determined based on the method reported by

144 (Zhishen, Mengcheng, \& Jianming, 1999) with slight modification. A series of

145 catechin solutions $(0-100 \mathrm{mg} / \mathrm{L})$ was prepared to establish the standard curve.

146 Briefly, $1 \mathrm{~mL}$ sample or blank was diluted with $250 \mu \mathrm{L}$ of distilled water, and then 75

$147 \mu \mathrm{L} \mathrm{NaNO}{ }_{2}(5 \%)$ was added. After $5 \mathrm{~min}, 150 \mu \mathrm{L} \mathrm{AlCl} 3(10 \%)$ was added. After

148 another $5 \mathrm{~min}, 500 \mu \mathrm{L}$ of $1 \mathrm{M} \mathrm{NaOH}$ was added and finally the solution was diluted

149 with $2 \mathrm{~mL}$ distilled water. After incubation for $30 \mathrm{~min}$ at room temperature, the

150 absorbance was read at $510 \mathrm{~nm}$ on the DR5000 Spectrophotometer (Hach Compary,

151 Germany). The total flavonoid content was calculated by comparing the readings

152 against the standard curve and expressed as mg catechin equivalent/g dry weight

153 (mg catechin/g DW). 
1542.5 Determination of 2,2-diphenyl-1-picryhydrazyl (DPPH) radical-scavenging 155 capacity

156 The DPPH assay described by (Brand-Williams, Cuvelier, \& Berset, 1995) was

157 modified and used to measure the radical scavenging capacity of potato peel extracts.

$158300 \mu \mathrm{L}$ sample or blank was mixed with $1 \mathrm{~mL}$ of $1 \mathrm{mM}$ solution of DPPH in ethanol.

159 The absorbance was read on the DR5000 Spectrophotometer (Hach Compary,

160 Germany), at $515 \mathrm{~nm}$ every $5 \mathrm{~min}$ until the reaction reached a plateau (around 70

$161 \mathrm{~min}$ ). The radical-scavenging activity (RSA) was calculated using the equation below

162 as a percentage of DPPH discoloration:

$$
R S A=\frac{\left(A_{\text {control }}\right)_{t=60 \mathrm{~min}}-\left(A_{\text {sample }}\right)_{t=60 \mathrm{~min}}}{\left(A_{\text {control }}\right)_{t=60 \mathrm{~min}}} \times 100
$$

163 where $A_{\text {sample }}$ is the absorbance of the sample at $515 \mathrm{~nm}$, and $A_{\text {control }}$ is the

164 absorbance of a blank at $515 \mathrm{~nm}$.

$165 \quad 2.6$ Extraction yield measurement

166 The yield measurement was carried out through freeze drying. Briefly, $10 \mathrm{~mL}$ of

167 potato peel extract was lyophilized and the residue was collected and weighed. The

168 extraction yield was calculated and displayed as mg (bioactive component)/g

169 (potato peels). Every sample was measured in triplicate. 
171 The particle size distribution was measured using a laser diffraction particle size

172 analyzer (LS-13-320, Backman Coulter Inc., Brea, CA) with the universal liquid

173 module. The mean and median of the particle size was calculated from the

174 triplicates.

1752.8 Isolation and quantification of individual phenolic acids

176 The HPLC analysis was performed on a Varian Pro Star HPLC system, equipped

177 with Polaris solvent delivery modules (Palo Alto, CA), employing a Acclaim C30

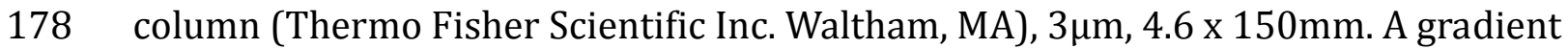

179 profile was developed for this test. In detail, the elution was carried out using a

180 binary gradient consisting of $2 \%$ acetic acid (A) and $100 \%$ acetonitrile (B). The

181 column temperature was set at $30^{\circ} \mathrm{C}$ and the flow rate was $0.5 \mathrm{~mL} / \mathrm{min}$. The solvent

182 gradient program was set as follows: $5 \%$ B for the first $5 \mathrm{~min}$, then increased to $100 \%$

183 over $25 \mathrm{~min}$. Then B was kept 100\% for $13 \mathrm{~min}$ and decreased to $5 \%$ over $5 \mathrm{~min}$. At

184 the end B was kept at $5 \%$ until 60 min. The injection volume was $10 \mu \mathrm{L}$ and all the

185 samples were filtered through a $0.45 \mu \mathrm{m}$ membrane. Gallic acid, sinapic acid, vanillic

186 acid, syringic acid, protocatechuic acid, p-coumaric acid and chlorogenic acid were

187 monitored at a wavelength of $280 \mathrm{~nm}$, while caffeic acid and ferulic acid were

188 detected at $320 \mathrm{~nm}$ using a Varian Pro Star 325 UV detector (Palo Alto, CA). The 
189 concentrations were calculated from standard curves prepared under the same

190 conditions.

1912.9 Scanning electron microscopy

192 Scanning electron microscopy (SEM) was carried out to provide a visual

193 confirmation of modification to the ultrastructure of potato peels. Samples were

194 mounted on aluminum stubs with double-sided carbon adhesive tabs, and sputter

195 coated with gold-palladium (60\%-40\%). Specimens were observed in a Hitachi

196 S3500N scanning electron microscope at an accelerating voltage of $5 \mathrm{kV}$.

$197 \quad 2.10$ Statistical analysis

198 All experiments were carried out in triplicate and the results were expressed as

199 mean \pm standard deviation. All the data were subjected to analysis of variance

$200(\mathrm{p}<0.05)$, and the results were processed by SPSS Version 23.0 (SPSS Inc., Chicago, IL, 201 USA).

$202 \quad 3$ Results and discussion

2033.1 Proximate composition of potato peels residue

204 The chemical composition of potato peels expressed as a percentage of weight is

205 shown in Table 1. Carbohydrates were found to be the main component accounting 
206 for $72.21-72.57 \%$ of the potato peels. Among the carbohydrates, $45.60-49.45 \%$ was

207 starch and 6.58-9.09\% was crude fiber. Lower protein and higher moisture were

208 observed compared with the data for samples obtained through abrasion and steam

209 peeling procedures (Camire, Violette, Dougherty, \& McLaughlin, 1997) . Similar ash,

210 moisture, fat, protein and total carbohydrate can be found in potato peel powders of

211 different particle size. However, more starch and lower crude fiber can be found in

212 lower particle size samples.

$213 \quad 3.2$ Effect of $\mathrm{NaOH}$ and homogenization pretreatment on the extract yield

214 As shown in Table 2, the extraction yield (EY) increased from $24.83 \mathrm{mg} / \mathrm{g}$ to

$215102.33 \mathrm{mg} / \mathrm{g}$ with $0.1 \mathrm{~mol} / \mathrm{L} \mathrm{NaOH}$ treatment for $18 \mathrm{~h}$, and improved a large amount

216 when treated by HPH. The combined treatment yielded the highest EY. With the

217 increase of $\mathrm{NaOH}$ treatment time from $6 \mathrm{~h}$ up to $24 \mathrm{~h}$, the EY increased slightly. The

218 homogenization process and concentration of $\mathrm{NaOH}$ have a significant impact on the

219 extraction yield, while the pretreatment time did not affect it significantly $(\mathrm{p}<0.05)$.

220 Similar trends of total phenolic content (TPC) and total flavonoid content (TFC) can

221 be observed from this table. The bound bioactive components, especially the

222 phenolic acid, were released with alkaline treatment and HPH process. The TPC and

223 TFC rose from $2.88 \mathrm{mg} / \mathrm{g}$ and $2.61 \mathrm{mg} / \mathrm{g}$ to $3.87 \mathrm{mg} / \mathrm{g}$ and $3.63 \mathrm{mg} / \mathrm{g}$ respectively

224 with $0.1 \mathrm{~mol} / \mathrm{L} \mathrm{NaOH}$ treatment for $18 \mathrm{~h}$. The HPH process augmented them to 3.67 
$225 \mathrm{mg} / \mathrm{g}$ and $3.11 \mathrm{mg} / \mathrm{g}$. Furthermore, the combined treatment can push the TPC up to

$2264.16 \mathrm{mg} / \mathrm{g}$ with $0.1 \mathrm{~mol} / \mathrm{L} \mathrm{NaOH}$ treatment for $18 \mathrm{~h}$, and the TFC up to $3.95 \mathrm{mg} / \mathrm{g}$

227 with $0.1 \mathrm{~mol} / \mathrm{L} \mathrm{NaOH}$ treatment for $12 \mathrm{~h}$. Higher TPC and TFC can be obtained with

2280.1 and $0.2 \mathrm{~mol} / \mathrm{L} \mathrm{NaOH}$ compared with 0.3 and $0.4 \mathrm{~mol} / \mathrm{L} \mathrm{NaOH}$, whether or not

229 they were treated by HPH. Consequently, the lower concentration alkaline treatment

230 can contribute more to the active component release process. Similarly, with the rise

231 in $\mathrm{NaOH}$ treatment time, no significant improvements of TPC or TFC were obtained.

232 This could be due to the process finishing in $18 \mathrm{~h}$ and some antioxidant component

233 being gradually oxidized after that. ANOVA $(\mathrm{p}<0.05)$ also showed that both TPC and

234 TFC were affected significantly by homogenization and $\mathrm{NaOH}$ concentration.

235 However, pretreatment time of $\mathrm{NaOH}$ only have significant effect on TFC. From Table

2362 , it can be seen that the combined extraction method did not improve the TPC and

237 TFC as much as the summation of two individual methods. One reason may be the

238 starch pastes formed during the direct alkaline extraction, because the major

239 component of the potato residue from the factory is starch. The starch pastes with a

240 high viscosity affected the extraction efficiency and inhibited the diffusion of the

241 extract (Zhou, Robards, Helliwell, \& Blanchard, 2004). This effect reduced the

242 velocity of the sample in the chamber, which in turn reduced the release of the active

243 component. This can also be supported by the finding that the particle size of the

244 control sample is lower than that of the samples treated by $\mathrm{NaOH}$. The other reason 
245 is that some kinds of phenolic acids were degraded during the extraction process

246 which was supported by the result of HPLC.

$247 \quad 3.3$ Effect of $\mathrm{NaOH}$ and homogenization pretreatment on the antioxidant of extracts

248 Table 2 also shows that the radical-scavenging capacity expressed by DPPH was

249 noticeably improved by $\mathrm{NaOH}$ and $\mathrm{HPH}$ treatment. The highest DPPH was 58.62

250 when the samples were processed by combined $\mathrm{HPH}$ and $0.2 \mathrm{~mol} / \mathrm{L} \mathrm{NaOH}$ treatment

251 for 2 pass cycles and $18 \mathrm{~h}$ respectively. HPH changes the physical structure of the

252 sample to obtain more active component, resulting in the increase of antioxidant

253 capacity. The $\mathrm{NaOH}$ treatment softens the cell wall to release the bound active

254 component. In conclusion, the $\mathrm{NaOH}$ and $\mathrm{HPH}$ treatment can be combined to

255 improve the efficiency of extraction except for improvement of anaerobic digestion

256 efficiency (Fang, Zhang, Zhang, Jin, Li, Zhang, et al., 2014; Zhang, Zhang, Zhang, Ma,

$257 \mathrm{Wu}, \& \mathrm{Ma}, 2012)$. The radical-scavenging capacity of extract from plants can be

258 improved by $\mathrm{HPH}$, which was also reported by $(\underline{\mathrm{Hu}, \mathrm{Nie}, \text { \& Xie, 2013 }})$. Varying

259 concentration did not significantly affect DPPH, which also agrees with the findings

260 of $(\underline{\mathrm{Hu}, \mathrm{Nie}, \& \mathrm{Xie}, 2013})$. Additionally, with the prolonging of treatment time, the

261 DPPH declined slightly because of the decomposition and oxidation of the active

262 components in the extraction. The homogenization and concentration of $\mathrm{NaOH}$

263 significantly affected the DPPH, while the NaoH pretreatment time did not. 
265 potato peels

266 SEM micrographs of $\mathrm{NaOH}$ and $\mathrm{HPH}$ treatment potato peels are shown in Fig. 1

267 (500x). A through C show the samples pretreated with $0,0.1$ and $0.4 \mathrm{~mol} / \mathrm{L} \mathrm{NaOH}$

268 without HPH treatment while D through F express the samples pretreated with 0 ,

2690.1 and $0.4 \mathrm{~mol} / \mathrm{L} \mathrm{NaOH}$ with $\mathrm{HPH}$ treatment. The structure of potato peels was

270 damaged by HPH. The elliptical shape granules in Fig. 1 D-F are starch; half of the

271 component in potato peels was starch (see Table 1), and starch tends to retain

272 granules after HPH (Guo, Zeng, Lu, Zhou, Zheng, \& Zheng, 2015; Le Thanh-Blicharz,

273 Lewandowicz, Baszczak, \& Prochaska, 2012). The crude fiber was broken and the

274 protein structure was changed; these segments adhered to the starch granules or

275 separated, as reported by (Sugumaran, Vimal, Kapur, \& Narula, 2015). During this

276 process, the phenolic acids and flavonoids, which had been bound to the fiber

277 structure, were released; this resulted in a dramatic increase of total phenolic acids

278 and total flavonoids. In Fig. 1, more small segments are observed with increasing

279 concentration of $\mathrm{NaOH}$ treatment. The reason could be that the alkaline treatment

280 may solubilize extracellular polymeric substance (Fang, et al., 2014). The ester link

281 was broken and the bound-form phenolic acids such as ferulic acid and p-coumaric

282 were released. We can conclude that the combined treatment of $\mathrm{NaOH}$ and $\mathrm{HPH}$

283 produced many smaller segments found in the micrographs. The cellular structure 
284 was altered by the treatment and more bioactive components were released during

285 this process. Additionally, some crystals can be seen after the $\mathrm{NaOH}$ pretreatment

286 and a large amount is observable when the concentration is $0.5 \mathrm{~mol} / \mathrm{L}$. These are

287 probably the $\mathrm{NaCl}$ crystals from the neutralized reaction of $\mathrm{NaOH}$ and $\mathrm{HCl}$, so the

288 amount increased with increased concentration. Similar structures were found by

289 (Eswaran, Stoops, \& Abtahi, 1980).

290 For a more specific analysis, the particle size of potato peels with different

291 treatment is shown in Fig. 2. Evidently, the HPH process reduced the mean particle

292 sizes from $206.40-266.80 \mu \mathrm{m}$ to $44.66-60.32 \mu \mathrm{m}$, with similar changes occurring in

293 the median value as well. This result is supported by the SEM measurement result

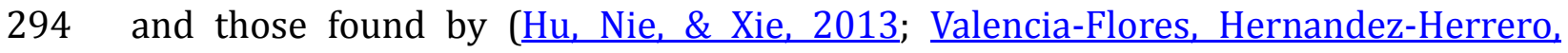

295 Guamis, \& Ferragut, 2013). It also can be concluded that the HPH process can reduce

296 the particle size of potato peels dramatically due to the strong shear and high impact

297 force broke the cell walls to generate the small cellulose fragment and smaller

298 sphere. On the other side, the effect of $\mathrm{NaOH}$ treatment on the particle size is not

299 significantly. It is supported by the SEM measurement result, we can see the $\mathrm{NaOH}$

300 treatment gained only small segments so that the mean and median of particle size

301 declined slightly. The reason may be during the treatment produced small segments

302 and swelled the other segments simultaneously. However, when the treatment time

303 was over $12 \mathrm{~h}$ the particle size became smaller compared to the short time 
304 treatment. Almost the same particle size can be obtained when they are carried out

305 with $\mathrm{HPH}$ and $\mathrm{NaOH}$ combined treatment.

3063.5 Effect of NaOH and homogenization pretreatment on the specific phenolic acid

307 Fig. 3. shows the results of HPLC analysis for extracts with different treatment

308 conditions and revealed the major phenolic acid changes under different treatments.

309 All treatments increased the phenolic yields to different degrees. The gallic acid

310 yield was the major portion in the extract, while the syringic acid was the lowest.

311 More chlorogenic acid and sinapic acid were produced with $\mathrm{NaOH}$ treatment while

312 the protocatechuic acid, caffeic acid and vanillic acid yields declined slightly. The

313 reason could be that $\mathrm{NaOH}$ can hydrolyze the bound acid and speed up the

314 degradation of caffeic acid significantly, which has been reported by(Nardini, Cirillo,

315 Natella, Mencarelli, Comisso, \& Scaccini, 2002) The NaOH treatment increased the

316 bound-form phenolic acid yield, which was mainly contributed by the increased

317 yields of ferulic acid, $p$-coumatic and syringic acid. This has been observed in the

318 report of (Nara, Miyoshi, Honma, \& Koga, 2006), in which the samples were treated

319 with $4 \mathrm{~mol} / \mathrm{L} \mathrm{NaOH}$ for 1 hour at room temperature. The yield of protocatechuic acid,

320 vanillic acid and caffeic acid, most of which are non-bound, can apparently be

321 improved by the HPH. 


\section{4 conclusions}

323 This study is the first time that HPH treatment was used to improve the extraction of

324 phenolic acid from potato peels residues. The total phenolic acid extraction yield can

325 be improved by the combined $\mathrm{NaOH}$ and $\mathrm{HPH}$ treatment. However, the $\mathrm{NaOH}$

326 concentration and treatment time were not the main factors affecting the extraction.

327 From the results of particle size and SEM measurements, it is clear that the HPH

328 process produced the smaller segments that significantly helped the release of the

329 active components. The HPLC measurement also demonstrated that the $\mathrm{NaOH}$ and

330 HPH treatment improved the extraction yields of most of the individual phenolic

331 acids. In conclusion, we have shown that the combined $\mathrm{NaOH}$ and HPH treatment is

332 an efficient method to promote the release and extraction of phenolic acids from

333 potato peel residues.

\section{$334 \quad 5$ Acknowledgements}

335 The authors thank Old Dutch Food Inc. (Roseville, MN, USA) for providing the 336 potato peels residues. This research is supported in part by the China Scholarship

337 Council, USDA NIFA, the Center for Biorefining at University of Minnesota and key

338 technology development and application for utilization and functional evaluation of

339 the hole wheat bran functional factors (2015DFA30540), international S\&T

340 cooperation program of China. 

of phytochemicals production from potato peel using subcritical water: Experimental and dynamic modeling. Journal of Supercritical Fluids, 90, 8-17. production from potato peel waste (PPW). Waste Management, 30(10), 1898-1902.

Bhattacharyya, S., Chakraborty, S., Datta, S., Drioli, E., \& Bhattacharjee, C. (2013). Production of total reducing sugar (TRS) from acid hydrolysed potato peels by sonication and its optimization. Environmental Technology, 34(9), 1077-1084.

Brand-Williams, W., Cuvelier, M. E., \& Berset, C. (1995). Use of a free radical method to evaluate antioxidant activity. LWT - Food Science and Technology, 28(1), 25-30.

Camire, M. E., Violette, D., Dougherty, M. P., \& McLaughlin, M. A. (1997). Potato Peel Dietary Fiber Composition: Effects of Peeling and Extrusion Cooking Processes. Journal of Agricultural and Food Chemistry, 45(4), 1404-1408.

Chen, M. S., Zhao, Y., \& Yu, S. J. (2015). Optimisation of ultrasonic-assisted extraction of phenolic compounds, antioxidants, and anthocyanins from sugar beet molasses. Food Chemistry, 172, 543-550.

dos Santos, T. C., Gomes, D. P. P., Bonomo, R. C. F., \& Franco, M. (2012). Optimisation of solid state fermentation of potato peel for the production of cellulolytic enzymes. Food Chemistry, 133(4), 1299-1304.

Eswaran, H., Stoops, G., \& Abtahi, A. (1980). SEM morphologies of halite (NaCl) in soils. Journal of Microscopy, 120(3), 343-352.

Fang, W., Zhang, P. Y., Zhang, G. M., Jin, S. G., Li, D. Y., Zhang, M. X., \& Xu, X. Z. (2014). Effect of alkaline addition on anaerobic sludge digestion with combined pretreatment of alkaline and high pressure homogenization. Bioresource Technology, 168, 167-172.

Farvin, K. H. S., Grejsen, H. D., \& Jacobsen, C. (2012). Potato peel extract as a natural antioxidant in chilled storage of minced horse mackerel (Trachurus trachurus): Effect on lipid and protein oxidation. Food Chemistry, 131(3), 843-851.

Friedman, M. (1997). Chemistry, Biochemistry, and Dietary Role of Potato Polyphenols. A Review. Journal of Agricultural and Food Chemistry, 45(5), 1523-1540.

Fry, S. C. (1986). Cross-Linking of Matrix Polymers in the Growing 
Cell-Walls of Angiosperms. Annual Review of Plant Physiology and Plant Molecular Biology, 37, 165-186. soluble drugs - reproducibility of small scale production. International Journal of Pharmaceutics, 196(2), 155-159. Structural and physicochemical properties of lotus seed starch treated with ultra-high pressure. Food Chemistry, 186, 223-230.

Hu, J. L., Nie, S. P., \& Xie, M. Y. (2013). High pressure homogenization increases antioxidant capacity and short-chain fatty acid yield of polysaccharide from seeds of Plantago asiatica L. Food Chemistry, 138(4), 2338-2345.

Kanatt, S. R., Chander, R., Radhakrishna, P., \& Sharma, A. (2005). Potato peel extract - a natural antioxidant for retarding lipid peroxidation in radiation processed lamb meat. Journal of Agricultural and Food Chemistry, 53(5), 1499-1504.

Le Thanh-Blicharz, J., Lewandowicz, G., Baszczak, W., \& Prochaska, K. (2012). Starch modified by high-pressure homogenisation of the pastes Some structural and physico-chemical aspects. Food Hydrocolloids, 27(2), 347-354.

Li, Y., Ruan, R., Chen, P. L., Liu, Z., Pan, X., Lin, X., Liu, Y., Mok, C., \& Yang, T. (2004). Enzymatic hydrolysis of corn stover pretreated by combined dilute alkaline treatment and homogenization. Transactions of the ASAE, 47(3), 821.

Liang, S. B., McDonald, A. G., \& Coats, E. R. (2014). Lactic acid production with undefined mixed culture fermentation of potato peel waste. Waste Management, 34(11), 2022-2027.

Maldonado, A. F. S., Mudge, E., Ganzle, M. G., \& Schieber, A. (2014). Extraction and fractionation of phenolic acids and glycoalkaloids from potato peels using acidified water/ethanol-based solvents. Food Research International, 65, 27-34.

McCrae, C. H. (1994). Homogenization of milk emulsions:use of microfluidizer. International Journal of Dairy Technology, 47(1), 28-31.

Mohdaly, A. A. A., Sarhan, M. A., Mahmoud, A., Ramadan, M. F., \& Smetanska, I. (2010). Antioxidant efficacy of potato peels and sugar beet pulp extracts in vegetable oils protection. Food Chemistry, 123(4), 1019-1026.

Mohdaly, A. A. A., Sarhan, M. A., Smetanska, I., \& Mahmoud, A. (2010). Antioxidant properties of various solvent extracts of potato peel, sugar beet pulp and sesame cake. Journal of the Science of Food and Agriculture, 90(2), 218-226. 
Nara, K., Miyoshi, T., Honma, T., \& Koga, H. (2006). Antioxidative activity of Biochemistry, 70(6), 1489-1491.

Nardini, M., Cirillo, E., Natella, F., Mencarelli, D., Comisso, A., \& Scaccini, C. (2002). Detection of bound phenolic acids: prevention by ascorbic acid and ethylenediaminetetraacetic acid of degradation of phenolic acids during alkaline hydrolysis. Food Chemistry, 79(1), 119-124.

Rehman, Z. U., Habib, F., \& Shah, W. H. (2004). Utilization of potato peels extract as a natural antioxidant in soy bean oil. Food Chemistry, 85(2), 215-220.

Singh, A., Sabally, K., Kubow, S., Donnelly, D. J., Gariepy, Y., Orsat, V., \& Raghavan, G. S. V. (2011). Microwave-Assisted Extraction of Phenolic Antioxidants from Potato Peels. Molecules, 16(3), 2218-2232.

Singh, P. P., \& Saldana, M. D. A. (2011). Subcritical water extraction of phenolic compounds from potato peel. Food Research International, 44(8), 2452-2458.

Singleton, V. L., Orthofer, R., \& Lamuela-Raventós, R. M. (1999). Analysis of total phenols and other oxidation substrates and antioxidants by means of Folin- Ciocalteu reagent. . Methods in enzymology, oxidants and antioxidants., 299 152-178.

Sugumaran, V., Vimal, K. K., Kapur, G. S., \& Narula, A. K. (2015). Preparation and morphological, thermal, and physicomechanical properties of polypropylene-potato peel biocomposites. Journal of Applied Polymer Science, 132(34).

Valencia-Flores, D. C., Hernandez-Herrero, M., Guamis, B., \& Ferragut, V. (2013). Comparing the Effects of Ultra-High-Pressure Homogenization and Conventional Thermal Treatments on the Microbiological, Physical, and Chemical Quality of Almond Beverages. Journal of Food Science, 78(2), E199-E205.

Wu, Z. G., Xu, H. Y., Ma, Q., Cao, Y., Ma, J. N., \& Ma, C. M. (2012). Isolation, identification and quantification of unsaturated fatty acids, amides, phenolic compounds and glycoalkaloids from potato peel. Food Chemistry, 135(4), 2425-2429.

Zhang, Y. X., Zhang, P. Y., Zhang, G. M., Ma, W. F., Wu, H., \& Ma, B. Q. (2012). Sewage sludge disintegration by combined treatment of alkaline plus high pressure homogenization. Bioresource Technology, 123, 514-519.

Zhishen, J., Mengcheng, T., \& Jianming, W. (1999). The determination of flavonoid contents in mulberry and their scavenging effects on superoxide radicals. Food Chemistry, 64(4), 555-559. 
Fig. 1. Scanning electron micrographs of potato peels of control (A), treatment with $0.1 \mathrm{~N} \mathrm{NaOH}(B), 0.5 \mathrm{~N} \mathrm{NaOH}$ (C), HPH (D), $0.1 \mathrm{~N} \mathrm{NaOH}+\mathrm{HPH}$ (E) and $0.5 \mathrm{~N} \mathrm{NaOH}$ (F) and all the $\mathrm{NaOH}$ treatment were processed for $18 \mathrm{~h}$..

Fig. 2. the effect of $\mathrm{NaOH}$ concentration (a) and $\mathrm{NaOH}$ treatment time (b) combined with HPH treatment on the mean and median of potato peels particle size.

Fig. 3. (a) HPLC chromatogram of the standard samples mix, peak 1, gallic acid; 2 , protocatechuic acid; peak 3 , chlorogenic acid ; peak 4, vanillic acid; peak 5, syring acid; peak 6, $p$-coumaric acid; peak 7 sinapic acid; peak 8, caffeic acid; peak 9 ferulic acid. (b) the effect of $\mathrm{NaOH}$ and $\mathrm{HPH}$ treatment on different phenolic compounds, the $\mathrm{NaOH}$ treatment was processed with $0.1 \mathrm{~N} \mathrm{NaOH}$ for $18 \mathrm{~h}$ 

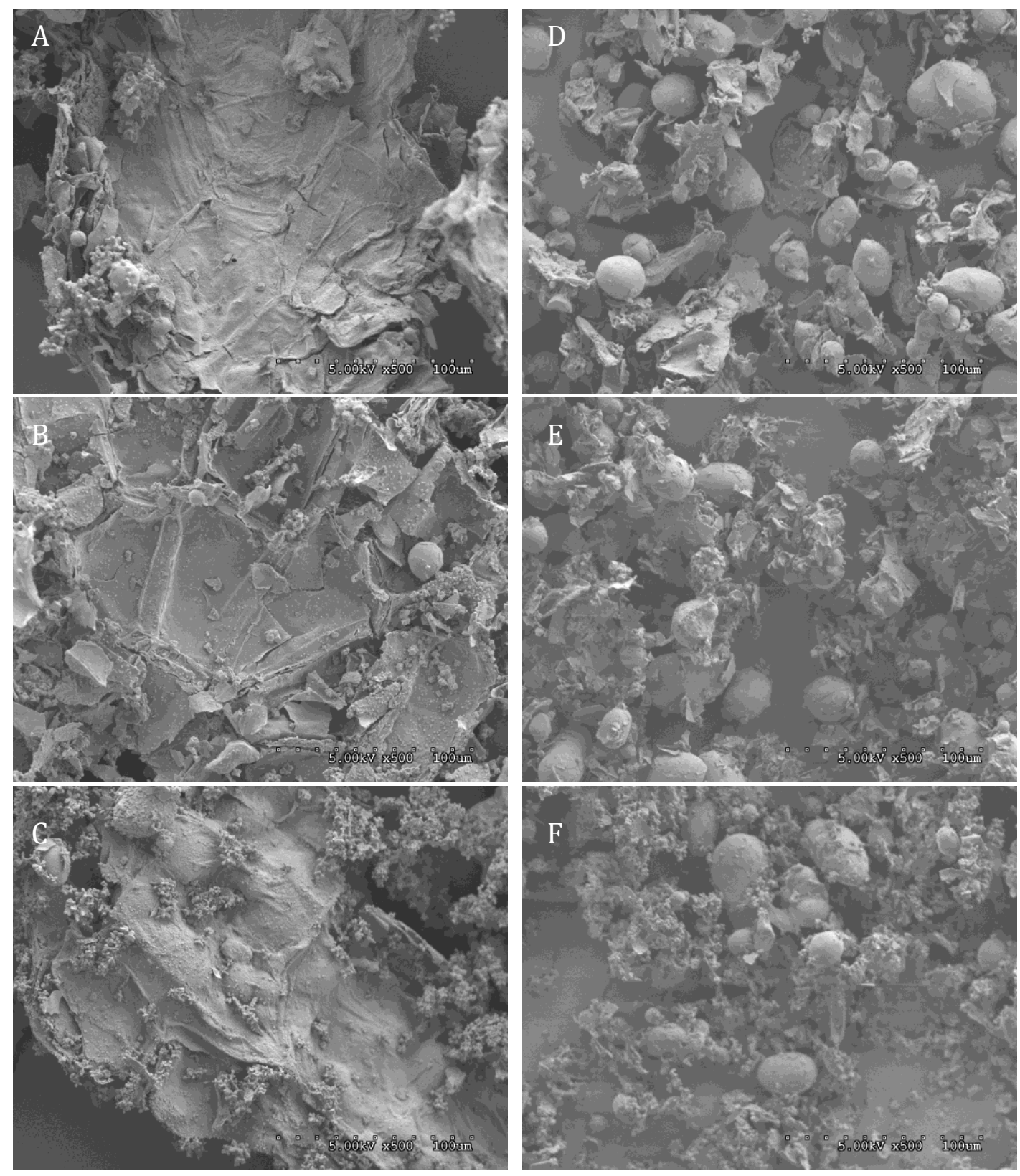

Fig. 1. Scanning electron micrographs of potato peels of control (A), treatment with $0.1 \mathrm{~N} \mathrm{NaOH}(B), 0.4 \mathrm{~N} \mathrm{NaOH}$ (C), HPH (D), $0.1 \mathrm{~N} \mathrm{NaOH}+\mathrm{HPH}$ (E) and 0.4N+HPH NaOH $(\mathrm{F})$, and all the $\mathrm{NaOH}$ treatment were processed for $18 \mathrm{~h}$. 


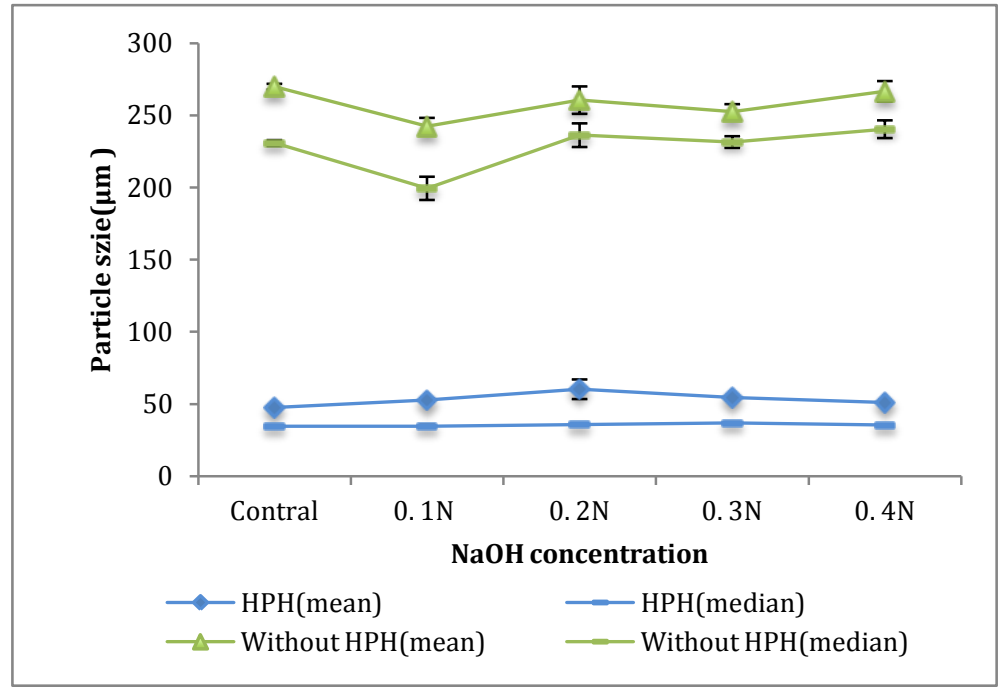

(a)

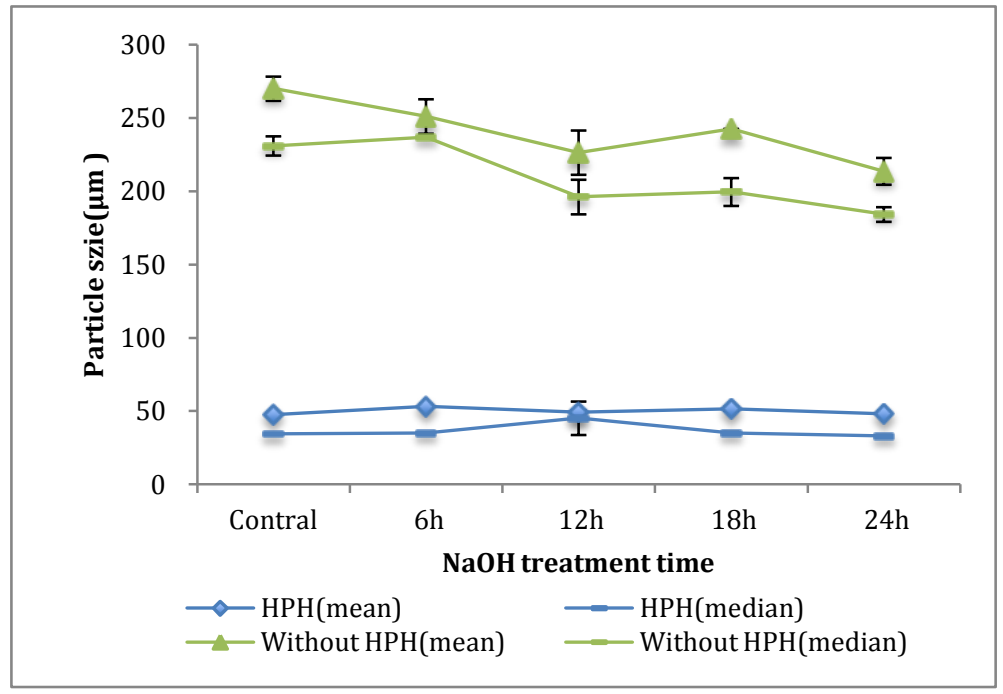

(b)

Fig. 2. the effect of $\mathrm{NaOH}$ concentration (a) and $\mathrm{NaOH}$ treatment time (b) combined with HPH treatment on the mean and median of potato peels particle size. 


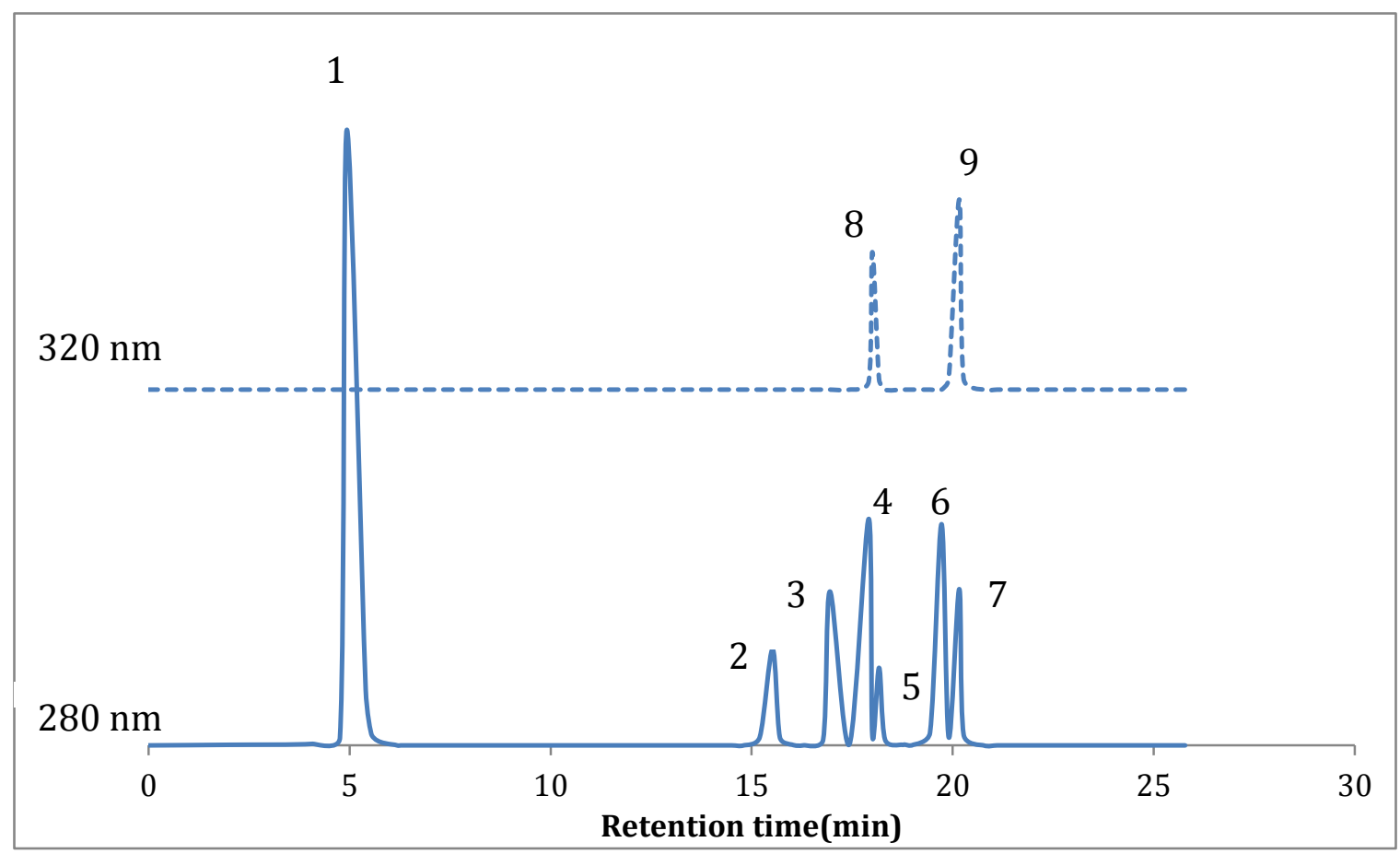

(a)

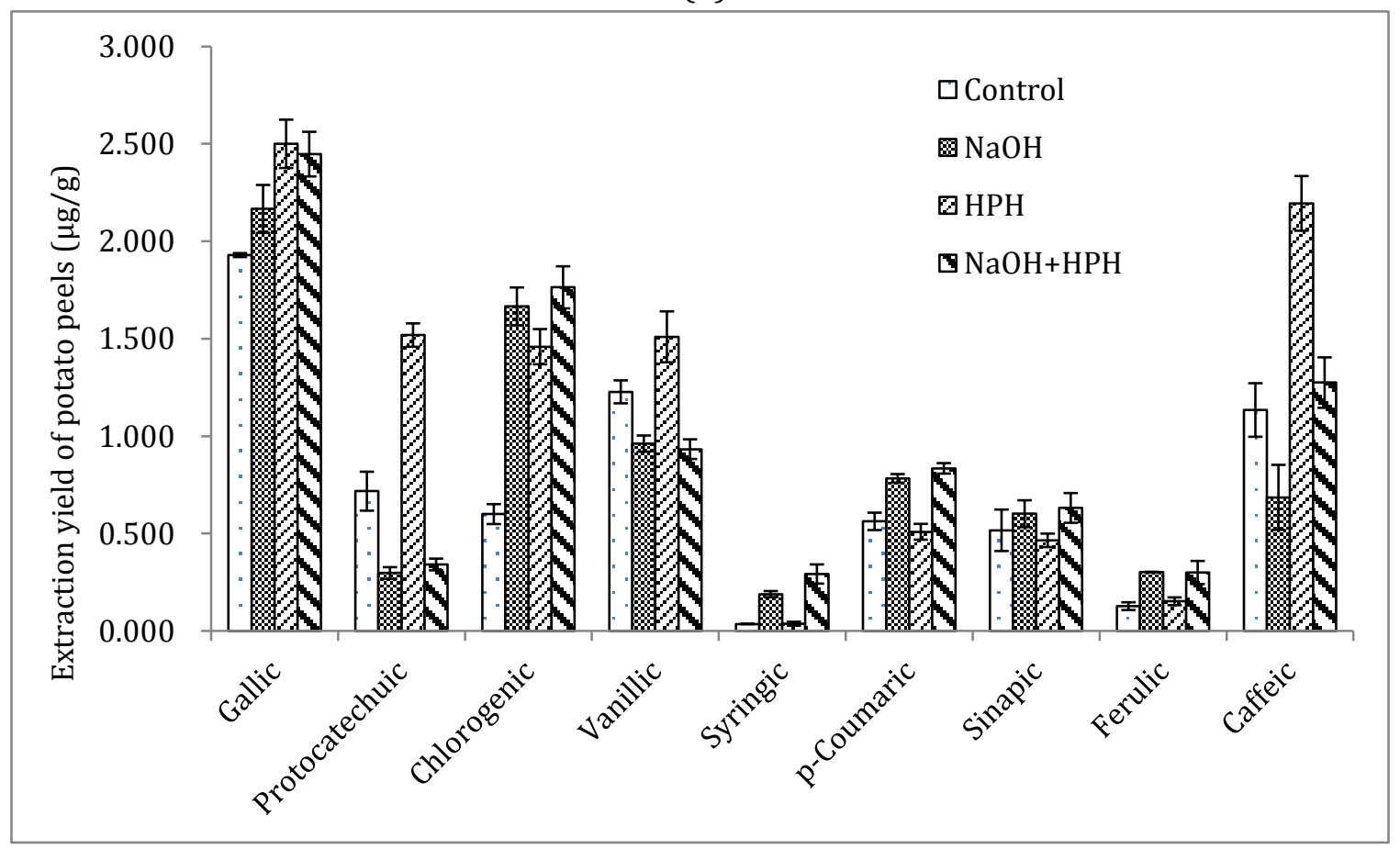

(b)

Fig. 3. (a) HPLC chromatogram of the standard samples mix, peak 1, gallic acid; 2, protocatechuic acid; peak 3, chlorogenic acid ; peak 4, vanillic acid; peak 5, syring acid; peak 6, p-coumaric acid; peak 7 sinapic acid; peak 8, caffeic acid; peak 9 ferulic acid. (b) the effect of $\mathrm{NaOH}$ and $\mathrm{HPH}$ treatment on different phenolic compounds, the $\mathrm{NaOH}$ treatment was processed with $0.1 \mathrm{~N} \mathrm{NaOH}$ for $18 \mathrm{~h}$ 


\begin{tabular}{lcc}
\hline Particle size & $125-212 \mu \mathrm{m}(\%)$ & $212-355 \mu \mathrm{m}(\%)$ \\
\hline Moisture & 6.00 & 5.55 \\
Carbohydrate & 72.57 & 72.21 \\
Starch & 49.40 & 45.60 \\
Fiber, Crude & 6.58 & 9.09 \\
Fat, ethyl ether & 1.04 & 1.33 \\
Protein N×6.25 & 12.90 & 13.60 \\
Ash & 7.49 & 7.31 \\
\hline
\end{tabular}

Table 1 Proximate composition of potato peels residue 


\begin{tabular}{|c|c|c|c|c|c|c|c|}
\hline Number & Homogenization & $\begin{array}{c}\mathrm{NaOH} \\
\text { Concentration } \\
(\mathrm{mol} / \mathrm{L})\end{array}$ & $\begin{array}{c}\mathrm{NaOH} \\
\text { Preatment } \\
\text { Time (h) }\end{array}$ & EY (mg/g) & TPC (mg/g) & $\mathrm{TFC}(\mathrm{mg} / \mathrm{g})$ & DPPH $(\%)$ \\
\hline 1 & 0 & 0 & 18 & $24.83 \pm 1.76 \mathrm{e}$ & $2.88 \pm 0.07 \mathrm{c}$ & $3.07 \pm 0.11 \mathrm{c}$ & $36.38 \pm 2.26 \mathrm{c}$ \\
\hline 2 & 0 & 0.1 & 18 & $102.33 \pm 1.04 \mathrm{~cd}$ & $3.87 \pm 0.04 \mathrm{ab}$ & $3.63 \pm 0.17 \mathrm{bc}$ & $46.14 \pm 1.25 b$ \\
\hline 3 & 0 & 0.2 & 18 & $94.50 \pm 3.50 \mathrm{~d}$ & $3.82 \pm 0.10 \mathrm{ab}$ & $3.40 \pm 0.04 \mathrm{c}$ & $45.67 \pm 0.50 \mathrm{~b}$ \\
\hline 4 & 0 & 0.3 & 18 & $97.17 \pm 3.61 \mathrm{~d}$ & $3.59 \pm 0.05 \mathrm{~b}$ & $3.12 \pm 0.24 \mathrm{c}$ & $44.91 \pm 2.36 \mathrm{~b}$ \\
\hline 5 & 0 & 0.4 & 18 & $103.50 \pm 3.00 \mathrm{~cd}$ & $3.56 \pm 0.15 b$ & $3.12 \pm 0.06 \mathrm{c}$ & $44.25 \pm 3.06 \mathrm{~b}$ \\
\hline 6 & 2 & 0 & 18 & $61.50 \pm 5.68 \mathrm{~d}$ & $3.67 \pm 0.06 \mathrm{~b}$ & $3.69 \pm 0.13 \mathrm{bc}$ & $45.51 \pm 3.32 \mathrm{~b}$ \\
\hline 7 & 2 & 0.1 & 18 & $104.50 \pm 4.36 \mathrm{~cd}$ & $4.16 \pm 0.22 \mathrm{a}$ & $3.90 \pm 0.09 \mathrm{bc}$ & $55.24 \pm 1.25 \mathrm{a}$ \\
\hline 8 & 2 & 0.2 & 18 & $101.33 \pm 1.61 \mathrm{~cd}$ & $4.09 \pm 0.02 \mathrm{ab}$ & $4.40 \pm 0.22 \mathrm{a}$ & $58.62 \pm 2.48 \mathrm{a}$ \\
\hline 9 & 2 & 0.3 & 18 & $136.17 \pm 3.32 \mathrm{a}$ & $3.93 \pm 0.15 \mathrm{ab}$ & $3.50 \pm 0.07 \mathrm{c}$ & $51.39 \pm 3.76 \mathrm{ab}$ \\
\hline 10 & 2 & 0.4 & 18 & $124.17 \pm 2.57 \mathrm{bc}$ & $3.78 \pm 0.11 \mathrm{ab}$ & $3.40 \pm 0.04 \mathrm{c}$ & $51.82 \pm 4.10 \mathrm{ab}$ \\
\hline 11 & 0 & 0.1 & 0 & $17.83 \pm 4.01 \mathrm{e}$ & $2.73 \pm 0.11 \mathrm{c}$ & $2.61 \pm 0.10 \mathrm{~d}$ & $29.59 \pm 2.31 \mathrm{c}$ \\
\hline 12 & 0 & 0.1 & 6 & $101.50 \pm 2.00 \mathrm{~cd}$ & $3.75 \pm 0.09 \mathrm{~b}$ & $3.32 \pm 0.21 \mathrm{c}$ & $45.35 \pm 2.44 b$ \\
\hline 13 & 0 & 0.1 & 12 & $103.67 \pm 5.80 \mathrm{~cd}$ & $3.83 \pm 0.18 \mathrm{ab}$ & $3.55 \pm 0.21 b c$ & $47.38 \pm 2.44 \mathrm{~b}$ \\
\hline $14(2)$ & 0 & 0.1 & 18 & $102.33 \pm 1.04 \mathrm{~cd}$ & $3.87 \pm 0.04 \mathrm{ab}$ & $3.63 \pm 0.17 \mathrm{bc}$ & $46.14 \pm 1.56 b$ \\
\hline 15 & 0 & 0.1 & 24 & $110.33 \pm 4.16 \mathrm{c}$ & $3.85 \pm 0.10 \mathrm{ab}$ & $3.43 \pm 0.08 \mathrm{c}$ & $42.64 \pm 2.13 b c$ \\
\hline 16 & 2 & 0.1 & 0 & $60.50 \pm 2.66 \mathrm{~d}$ & $3.60 \pm 0.26 b$ & $3.11 \pm 0.12 \mathrm{c}$ & $34.62 \pm 2.91 \mathrm{c}$ \\
\hline 17 & 2 & 0.1 & 6 & $100.00 \pm 1.82 \mathrm{~cd}$ & $3.83 \pm 0.04 \mathrm{ab}$ & $3.86 \pm 0.05 \mathrm{bc}$ & $56.38 \pm 2.43 \mathrm{a}$ \\
\hline 18 & 2 & 0.1 & 12 & $104.83 \pm 7.26 \mathrm{~cd}$ & $4.09 \pm 0.19 \mathrm{ab}$ & $3.95 \pm 0.23 b$ & $54.84 \pm 1.51 \mathrm{ab}$ \\
\hline $19(7)$ & 2 & 0.1 & 18 & $104.50 \pm 4.36 \mathrm{~cd}$ & $4.16 \pm 0.22 \mathrm{a}$ & $3.90 \pm 0.09 \mathrm{bc}$ & $55.24 \pm 1.25 \mathrm{a}$ \\
\hline 20 & 2 & 0.1 & 24 & $118.17 \pm 5.25 \mathrm{bc}$ & $4.02 \pm 0.08 \mathrm{ab}$ & $3.68 \pm 0.15 b c$ & $55.84 \pm 3.63 \mathrm{a}$ \\
\hline
\end{tabular}

*Mean \pm standard deviations within columns for each experiment are significantly different ( $\mathrm{p}<0.05$, Tukey HSD test) when followed by different letters.

Table 2 The results of extraction yield (EY), total phenolic content (TPC), total flavonoid content (TFC) and DPPH 
radical-scavenging capacity (DPPH) under different treatment condition 